\title{
Noncardiothoracic nonobstetric surgery in mild-to-moderate pulmonary hypertension
}

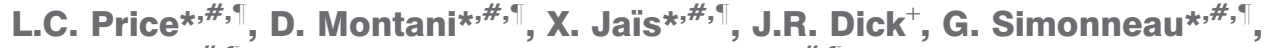 \\ O. Sitbon*,\#, , F.J. Mercier ${ }^{+}$and M. Humbert*,\#,
}

ABSTRACT: The anaesthetic management and follow-up of well-characterised patients with pulmonary arterial hypertension presenting for noncardiothoracic nonobstetric surgery has rarely been described.

The details of consecutive patients and perioperative complications during the period January 2000 to December 2007 were reviewed. Repeat procedures in duplicate patients were excluded. Longer term outcomes included New York Heart Association (NYHA) functional class, 6-min walking distance and invasive haemodynamics.

A total of 28 patients were identified as having undergone major (57\%) or minor surgery under general (50\%) and regional anaesthesia. At the time of surgery, $75 \%$ of patients were in NYHA functional class I-II. Perioperative deaths occurred in 7\%. Perioperative complications, all related to pulmonary hypertension, occurred in $29 \%$ of all patients and in $17 \%$ of those with no deaths during scheduled procedures. Most $(n=11,92 \%)$ of the complications occurred in the first $48 \mathrm{~h}$ following surgery. In emergencies $(n=4)$, perioperative complication and death rates were higher (100 and $50 \%$, respectively; $p<0.005$ ). Risk factors for complications were greater for emergency surgery $(p<0.001)$, major surgery $(p=0.008)$ and a long operative time (193 versus $112 \mathrm{~min}$;

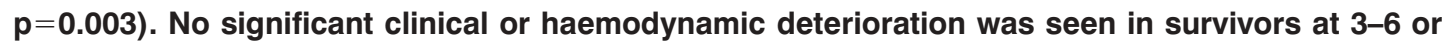
12 months of post-operative follow-up.

Despite optimal management in this mostly nonsevere pulmonary hypertension population, perioperative complications were common, although survivors remained stable. Emergency procedures, major surgery and long operations were associated with increased risk.

KEYWORDS: Anaesthesia, perioperative complications, perioperative mortality, pulmonary hypertension, pulmonary hypertensive crisis, right ventricular failure

$\mathbf{P}$ ulmonary hypertension $(\mathrm{PH})$ is defined by a mean resting pulmonary arterial pressure $\left(\bar{P}_{\mathrm{pa}}\right)$ of $\geqslant 25 \mathrm{mmHg}$ with a pulmonary capillary wedge pressure $(P \mathrm{pcw})$ of $\leqslant 15 \mathrm{mmHg}$ [1]. Pulmonary arterial hypertension $(\mathrm{PAH})$ defines a subgroup characterised by vascular cell proliferation and remodelling of low-resistance pulmonary arteries that causes elevated pulmonary vascular resistance (PVR), ultimately leading to right heart failure and death [1-3]. PAH is classified into idiopathic $\mathrm{PAH}$, heritable $\mathrm{PAH}$ and $\mathrm{PAH}$ associated with conditions such as connective tissue diseases, portal hypertension and HIV infection, amongst others [4]. Survival remains poor, with a $15 \%$ mortality rate at $1 \mathrm{yr}$ despite modern treatment [5]; however, increasingly, more types of therapy are available. Although $\mathrm{PAH}$ remains a rare disease, the most recent prevalence is increased, compared to previous eras, at 15 per million population in France [6].

Reflecting this increasing global health burden, patients are likely to present not only to $\mathrm{PH}$ referral units but also to nonspecialist centres for emergency and non-emergency surgery. Patients with $\mathrm{PH}$ represent one of the highest-risk groups of patients undergoing both cardiac [7] and noncardiac surgery [8-11], despite advances in perioperative monitoring and treatment. Potentially fatal complications relate to the consequences of rightsided circulatory failure, which may be precipitated by reduced right ventricular contractility, excessive volume loading or causes of further right ventricular pressure overload. A common mode of death appears to be minor stimulation resulting in tachycardia or increased PVR, followed by refractory hypotension, hypoxia and ultimately
AFFILIATIONS

*Faculté de Médecine, University

Paris-Sud, Kremlin-Bicêtre,

\#Service de Pneumologie et

Réanimation Respiratoire, Centre

National de Référence de

I'Hypertension Pulmonaire Sévère

Hôpital Antoine Béclère,

'Département d'Anesthésie-

Réanimation, Université Paris-Sud,

Hôpital Antoine-Béclère, Assistance

Publique - Hôpitaux de Paris,

Clamart, and

"INSERM Unité 999, Hypertension

Artérielle Pulmonaire,

Physiopathologie et Innovation

Thérapeutique, Institut Paris-Sud

d'Innovation Thérapeutique, Centre

Chirurgical Marie-Lannelongue, Le

Plesssis-Robinson, France.

\section{CORRESPONDENCE}

M. Humbert

Centre National de Référence de

I'Hypertension Artérielle Pulmonaire,

Service de Pneumologie, Hôpital

Antoine-Béclère, Assistance Publique

- Hôpitaux de Paris

Université Paris-Sud 11

157 rue de la Porte de Trivaux

92140 Clamart

France

E-mail: marc.humbert@abc.aphp.fr

Received:

July 162009

Accepted after revision:

Oct 132009

First published online:

Nov 062009 
cardiovascular collapse $[12,13]$ due to a downwards spiral of worsening right ventricular function [14]. Perioperative increases in PVR may be precipitated by hypoxia [15], hypercapnia [16], high airway plateau pressure due to the effects of positive-pressure mechanical ventilation [17] and atelectasis or may follow acute pulmonary embolism [18]. Such $\mathrm{PH}$ complications, including death, may occur up to 1 week post-operatively [19, 20], or even later, reported following delivery by Caesarean section [21, 22]. Perioperative measures may be utilised to prevent rapid haemodynamic deterioration in the setting of right ventricular failure (RVF). These include the use of pulmonary vasodilator therapies to minimise right ventricular afterload [19, 23, 24], the avoidance of excessive fluid administration that may overload the right ventricle, maintaining appropriate systemic perfusion pressure for adequate coronary perfusion and enhancing myocardial contractility [25].

There have been very few studies of well-characterised patients with $\mathrm{PH}$ undergoing noncardiothoracic nonobstetric surgery. Perioperative mortality and complication rates have been described in one previous study as 7 and $42 \%$, respectively [9], and 14 and $18 \%$ in a further smaller study [11]. Whereas perioperative care is likely to vary between institutions, further to the nature of the surgical procedure itself, it is not clear whether other aspects of anaesthetic or perioperative care may influence short-term outcomes in these patients. Furthermore, it is unclear whether operative procedures have implications on longer term $\mathrm{PH}$ end-points. It was, therefore, sought to describe the cohort of $\mathrm{PH}$ patients undergoing surgery at the French Reference Centre for Pulmonary Hypertension (University of Paris-South 11, Antoine Béclère Hospital, Clamart, France), details of their perioperative management and longer term $\mathrm{PH}$ outcomes.

\section{METHODS}

\section{Subjects}

Retrospective data were reviewed from patients referred to the French Reference Centre for Pulmonary Hypertension who had undergone general (GA) and regional anaesthesia (RA) for noncardiothoracic nonobstetric surgery between January 1, 2000 and December 31, 2007. Patients were included if a diagnosis of precapillary $\mathrm{PH}$ was confirmed before surgery by right heart catheterisation. Patients with chronic thromboembolic pulmonary hypertension (CTEPH) not amenable to endarterectomy were also included. Exclusion criteria included patients aged $<18$ yrs, those with $\mathrm{PH}$ due to left heart disease and those undergoing surgery for cardiothoracic or obstetric procedures. All clinical characteristics at diagnosis and follow-up were stored in the Registry of the French Network of Pulmonary Hypertension. This registry was set up in agreement with French bioethics laws (French Data Protection Authority, Paris, France), and all patients gave their informed consent [6].

\section{Clinical and functional assessment}

Patient demographics, aetiology of $\mathrm{PH}$, clinical features and major comorbid conditions were recorded at the latest timepoint prior to surgery, and at the 3-6 and 6-12 month evaluation following surgery. Clinical status was assessed using modified New York Heart Association (NYHA) functional class $[4,26]$ and the non-encouraged 6-min walking test, performed according to American Thoracic Society recommendations [27].

\section{Haemodynamic measurements}

Details of preoperative haemodynamic evaluation by right heart catheterisation were recorded for all subjects according to a previously described protocol [28]. Precapillary $\mathrm{PH}$ was defined as a $\bar{P}_{\text {pa }}$ of $\geqslant 25 \mathrm{mmHg}$ with a normal $P$ pcw of $\leqslant 15 \mathrm{mmHg} . \bar{P}_{\mathrm{pa}}, P_{\mathrm{pcw}}$, right atrial pressure and mixed venous oxygen saturation $\left(\mathrm{S}_{\mathrm{v}}, \mathrm{O}_{2}\right)$ were recorded. Cardiac index $(\mathrm{CI})$ was measured using the standard thermodilution technique. The indexed pulmonary vascular resistance (PVRI) was calculated as $\left(\bar{P}_{\mathrm{pa}}-\mathrm{P}_{\mathrm{pcw}}\right) / \mathrm{CI}$.

\section{Intra-operative factors}

Anaesthetic and surgical charts were examined to determine the nature of the operative procedure, the occurrence of emergency surgery and operative time (from induction of anaesthesia until extubation or end of surgery). Major surgery was defined to include major laparotomy, hysterectomy, mastectomy and major orthopaedic surgery, and minor surgery to include hernia repair, appendicectomy and extremity orthopaedic surgery. RA was defined as neuraxial blockade or other regional blockade. Details of venous access, intra-operative haemodynamic monitoring and, for procedures under GA, ventilator settings, mean intra-operative fractional inspired oxygen concentration $\left(\mathrm{FI}, \mathrm{O}_{2}\right)$, peak end-expiratory carbon dioxide level, peak airway pressure (in centimetres of water) and the use of nitrous oxide as a supplementary anaesthetic agent were recorded.

\section{Perioperative complications}

Perioperative complications were defined as those occurring during surgery or in the 28-day post-operative period. Perioperative complications related to $\mathrm{PH}$ were recorded from operative charts and medical notes. Non-PH complications were also noted. PH complications with increased right ventricular afterload leading to RVF, cardiogenic shock and ventilation/perfusion mismatch were of varying severity, and were defined as follows. Major PH complications were defined by the occurrence of death or severe acute right heart failure (clinical signs of low cardiac output (CO) and RVF) requiring vasopressors, inotropes, inhaled nitric oxide and/or additional pulmonary vasodilator therapy (intravenous epoprostenol or nebulised iloprost). Minor PH complications were defined as hypoxia requiring an escalation of the mode of ventilation, isolated hypotension or RVF not requiring the use of continuous infusions of vasopressors or inotropes.

\section{Statistical analysis}

Statistical analysis was performed using StatView version 5.0 (Abacus Concepts, Inc., Berkeley, CA, USA). Data are presented as mean $\pm \mathrm{SD}$ and median (range) for parametric and nonparametric data, respectively. Statistical analysis was performed using parametric tests (Fisher's exact test and paired t-test) or nonparametric tests (Mann-Whitney U-test for unpaired data and Wilcoxon matched-pair test for paired data), as appropriate. The distribution of qualitative data was assessed using Pearson's Chi-squared test with Yates's correction for continuity or Fisher's exact test as appropriate. 
Multivariate analysis was not performed because of the small number of procedures as compared to the number of risk factors identified on univariate analysis. A p-value of $<0.05$ was considered significant.

\section{RESULTS}

\section{Preoperative patient characteristics}

A total of 28 procedures were identified in 28 individual consecutive patients with idiopathic PAH ( $\mathrm{P}=10 ; 36 \%)$, associated PAH $(n=10 ; 36 \%$; comprising five portopulmonary, three connective tissue disease-associated and two HIVassociated PAH) and CTEPH $(n=8 ; 28 \%)$. The mean age of the patients was $53 \pm 16 \mathrm{yrs}$, with a female predominance $(57 \%)$. At the time of surgery, patients were in NYHA functional class I-II $(n=21 ; 75 \%)$ and class III $(n=7 ; 25 \%)$, with no patients in class IV, and the 6-min walking distance (6MWD) was $388 \pm 114 \mathrm{~m}$. Preoperative haemodynamics showed a $\bar{P}_{\text {pa }}$ of $43 \pm 12 \mathrm{mmHg}$, normal CI of $3.25 \pm 0.68 \mathrm{~L} \cdot \mathrm{min}^{-1} \cdot \mathrm{m}^{-2}$ and low $\mathrm{Sv}, \mathrm{O}_{2}(66 \pm 6 \%)$. Of the patients, $57 \%$ were on specific $\mathrm{PAH}$ therapy (table 1).

\section{Operative characteristics}

Of 28 procedures performed, 16 were abdominal surgery (nine inguinal hernias, one umbilical hernia, two laparoscopic cholecystectomies, one splenectomy, one open appendicectomy and two major bowel resections), eight orthopaedic procedures (of which four were major hip surgery and two major knee surgery), two mastectomies and two hysterectomies. According to the present definitions, 16 (57\%) were major and $12(43 \%)$ minor surgical procedures. A total of 14 procedures were performed under GA and 14 under RA. Four were emergency procedures, all performed under GA (hip hemiarthoplasty, bowel resection, laparotomy and appendicectomy).

\section{Anaesthesia characteristics}

For the 14 patients that had procedures under GA, all patients received opioids and propofol for induction of anaesthesia, and anaesthesia was maintained with sevoflurane (10 out of 14), isoflurane (two out of 14) or desflurane (two out of 14). Nitrous oxide was used as a supplemental anaesthetic agent in four patients, and the intra-operative $\mathrm{FI}_{1} \mathrm{O}_{2}$ was $0.60 \pm 0.17$ (table 2).

RA consisted of neuraxial blockade in 11 out of 28 patients (spinal anaesthesia in two and combined spinal-epidural anaesthesia in nine), and three other regional blocks (supraclavicular block, femoral block and lumbar plexus block) were combined with sedation in all three cases. For patients undergoing neuraxial blockade $(n=11)$, the spinal needles were $27 \mathrm{G}$ in size, and the spinal doses used were $4.8(3.0$ 7.5) $\mu$ g sufentanil (data available for $n=9$ ) combined with $0.5 \%$ heavy bupivacaine, and epidural top-ups used $2 \%$ lidocaine in all patients. No patients required conversion to GA. All of those previously on warfarin $(n=5)$ were switched to lowmolecular-weight (LMW) heparin (prophylactic dose) preoperatively, and there were no reported bleeding complications relating to the site of regional blockade, including in the patients receiving continuous intravenous epoprostenol.

There was no significant age or sex difference, or 6MWD or NYHA functional class difference, between those undergoing
GA and RA (table 1). As compared to RA, patients that had procedures under GA showed less severe haemodynamic impairment, with a significantly lower $\bar{P}_{\text {pa }}(36 \pm 10$ versus $48 \pm 11 \mathrm{mmHg} ; \mathrm{p}=0.003)$ and PVRI $(7.2 \pm 2.9$ versus $13.9 \pm 5.5 \mathrm{WU}$ (Wood units) $\cdot \mathrm{m}^{-2} ; \mathrm{p}=0.0003$ ) and a higher $\mathrm{CI}$ $(3.6 \pm 0.6$ versus $2.94 \pm 0.6 ; p=0.009)$. Patients undergoing RA were more likely to be on specific PAH therapy than those under GA (86 versus 29\%; $\mathrm{p}=0.002$ ).

\section{Perioperative complications}

Perioperative complications relating to $\mathrm{PH}$ occurred in eight $(29 \%)$ out of 28 procedures (table 3 ). There were no reported non-PH complications. Two $(7 \%)$ deaths occurred in the 28 procedures performed, due to refractory right heart failure in

\begin{tabular}{|c|c|c|c|c|}
\hline & All patients & $\mathrm{GA} \pm \mathrm{RA}$ & RA alone & p-value \\
\hline Surgical cases & 28 & 14 & 14 & \\
\hline Age at surgery yrs & $53 \pm 16$ & $53 \pm 15$ & $53 \pm 17$ & 0.89 \\
\hline Female sex & $16(57)$ & $8(57)$ & $8(57)$ & 1 \\
\hline \multicolumn{5}{|l|}{ PH type } \\
\hline Idiopathic PAH & $10(36)$ & $2(14)$ & $8(57)$ & 0.03 \\
\hline Associated PAH ${ }^{\#}$ & $10(36)$ & $8(57)$ & $2(14)$ & \\
\hline CTEPH & $8(28)$ & $4(29)$ & $4(29)$ & \\
\hline \multicolumn{5}{|l|}{ Specific therapy } \\
\hline No & $12(43)$ & $10(71)$ & $2(14)$ & 0.002 \\
\hline Yes & $16(57)$ & $4(29)$ & $12(86)$ & \\
\hline Bosentan & 10 & 8 & 2 & \\
\hline Sildenafil $\|^{\bullet}$ & 2 & 1 & 1 & \\
\hline Epoprostenol" & 5 & 1 & 4 & \\
\hline Other prostanoids $^{+}$ & 2 & 1 & 1 & \\
\hline $\mathrm{CCBs}$ & 1 & 0 & 1 & \\
\hline \multicolumn{5}{|l|}{ NYHA class } \\
\hline$|-| \mid$ & $21(75)$ & $11(79)$ & $10(71)$ & 0.66 \\
\hline III & $7(25)$ & $3(21)$ & $4(29)$ & \\
\hline 6MWD m & $388 \pm 114$ & $394 \pm 94$ & $383 \pm 133$ & 0.81 \\
\hline \multicolumn{5}{|l|}{ Haemodynamics } \\
\hline $\bar{P}$ pa $\mathrm{mmHg}$ & $43 \pm 12$ & $36 \pm 11$ & $49 \pm 9.5$ & 0.003 \\
\hline Pra $\mathrm{mmHg}$ & $6 \pm 4$ & $5 \pm 3$ & $7 \pm 4$ & 0.08 \\
\hline Ppow mmHg & $8.8 \pm 3$ & $8.5 \pm 3$ & $8.9 \pm 3$ & 0.77 \\
\hline $\mathrm{Cl} \mathrm{L} \cdot \mathrm{min}^{-1} \cdot \mathrm{m}^{-2}$ & $3.25 \pm 0.68$ & $3.60 \pm 0.62$ & $2.93 \pm 0.58$ & 0.009 \\
\hline $\mathrm{SVI} \mathrm{mL} \cdot \mathrm{m}^{-2}$ & $42 \pm 10$ & $44 \pm 9$ & $39 \pm 11$ & 0.33 \\
\hline PVRI WU $\cdot \mathrm{m}^{-2}$ & $11.1 \pm 5.7$ & $7.1 \pm 3.2$ & $14.5 \pm 5.0$ & $<0.001$ \\
\hline${\mathrm{Sv}, \mathrm{O}_{2}}_{\%}$ & $66 \pm 6$ & $70 \pm 2$ & $64 \pm 7$ & 0.04 \\
\hline
\end{tabular}

Data are presented as $n$, mean $\pm S D$ or $n(\%)$, unless otherwise stated. Means were compared using unpaired t-tests. $\mathrm{PH}$ : pulmonary hypertension; $\mathrm{PAH}$ : pulmonary arterial hypertension; CTEPH: chronic thromboembolic pulmonary hypertension; CCB: calcium channel blocker; NYHA: New York Heart Association; 6MWD: 6-min walking distance; $\bar{P}$ pa: mean pulmonary arterial pressure; Pra: right atrial pressure; $P$ pcw: pulmonary capillary wedge pressure; $\mathrm{Cl}$ : cardiac index; SVI: stroke volume index; PVRI: indexed pulmonary vascular resistance; WU: Wood unit; $\mathrm{S}_{\mathrm{V}} \mathrm{O}_{2}$ : mixed venous oxygen saturation. \#: comprising five portopulmonary hypertension, three connective tissue disease-associated PAH and two HIV-associated PAH patients; " : includes patients on combination therapy; ${ }^{+}$: including beraprost and iloprost. 


\begin{tabular}{|c|c|c|c|c|}
\hline \multirow[t]{2}{*}{ TABLE 2} & \multirow[b]{2}{*}{ All patients } & $\begin{array}{l}\text { e pulmona } \\
\text { ons during } \\
\text { operative }\end{array}$ & $\begin{array}{l}\text { hyperten } \\
\text { general } \\
\text { actors }\end{array}$ & \multirow[b]{2}{*}{ p-value } \\
\hline & & POCs & No POCs & \\
\hline Patients & 28 & 8 & 20 & \\
\hline Emergency surgery & $4(14)$ & $4(50)$ & 0 & $<0.001$ \\
\hline Major surgery & $16(57)$ & $8(100)$ & $8(40)$ & 0.008 \\
\hline Minor surgery & $12(43)$ & 0 & $12(60)$ & \\
\hline GA & $14(50)$ & $6(75)$ & $8(40)$ & 0.12 \\
\hline RA & $14(50)$ & $2(25)$ & $12(60)$ & \\
\hline Operative time min & $133(45-465)$ & $193(120-420)$ & $112(45-465)$ & 0.003 \\
\hline \multicolumn{5}{|l|}{ Additional monitoring } \\
\hline CVP/arterial line ${ }^{\#}$ & 3 & 3 & 0 & \\
\hline $\mathrm{CO}^{\circ}$ & 4 & 3 & 1 & \\
\hline \multicolumn{5}{|l|}{$\begin{array}{l}\text { GA patient } \\
\text { characteristics }\end{array}$} \\
\hline $\mathrm{Fl}, \mathrm{O}_{2}$ & $0.60 \pm 0.17$ & $0.60 \pm 0.12$ & $0.59 \pm 0.20$ & 0.90 \\
\hline Use of nitrous oxide & 4 & 3 & 1 & \\
\hline Peak $P \mathrm{ET}, \mathrm{CO}_{2} \mathrm{mmHg}$ & $36.1 \pm 5.4$ & $38.6 \pm 6.7$ & $34.1 \pm 3.5$ & 0.17 \\
\hline Peak $P$ aw $\mathrm{cmH}_{2} \mathrm{O}$ & $20.8 \pm 6.8$ & $22.4 \pm 8.8$ & $19.6 \pm 5.0$ & 0.51 \\
\hline \multicolumn{5}{|c|}{ 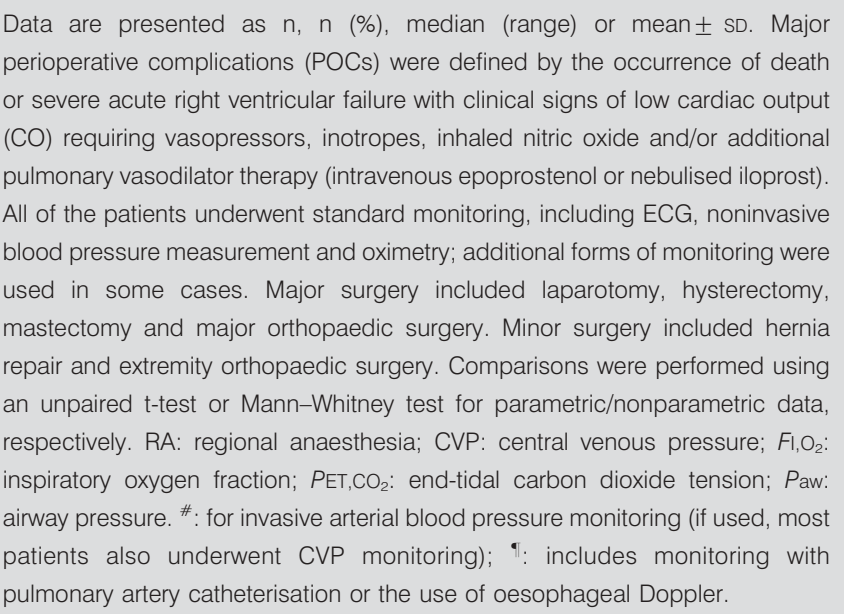 } \\
\hline
\end{tabular}

both cases: one intra-operatively, and the other at day 11. In the four emergency procedures, perioperative complications relating to $\mathrm{PH}(\mathrm{n}=4 ; 100 \%)$, including death $(n=2 ; 50 \%)$, occurred more frequently than in the non-emergency procedures (with four $(17 \%)$ out of 24 complications and no deaths; $\mathrm{p}<0.001)$ (table 2). More patients that had $\mathrm{PH}$-related perioperative complications had undergone major surgery compared to minor surgery (eight (50\%) out of 16 and none out of 12, respectively; $\mathrm{p}=0.008$ ) (table 2 ). Mortality related to major surgery was two (13\%) out of 16 compared to no deaths in patients undergoing minor surgery.

Most of the complications occurred during the procedure or during the following $48 \mathrm{~h}$ (seven (88\%) out of eight). Complications included three patients with severe acute right heart failure (following which two died), three cases of isolated hypotension and two of severe hypoxaemia. One death occurred at the time of surgery due to refractory right heart failure (patient No. 5), and the other (patient No. 8) was due to ongoing PH and RVF at day 11 post-operatively (table 4).

\begin{tabular}{|c|c|c|c|c|}
\hline \multirow[t]{2}{*}{ TABLE 3} & $\begin{array}{l}\text { ative }{ }^{\#} \text { pu } \\
\text { omplicati }\end{array}$ & $\begin{array}{l}\text { nary hyp } \\
\text { s: patient }\end{array}$ & $\begin{array}{l}\text { ension ( } P \\
\text { ctors }\end{array}$ & \multirow[b]{2}{*}{$p$-value } \\
\hline & All patients & POCs & No POCs & \\
\hline Patients & $28(100)$ & $8(29)$ & $20(71)$ & \\
\hline Age yrs & $53 \pm 16$ & $52 \pm 18$ & $54 \pm 15$ & 0.76 \\
\hline \multicolumn{5}{|l|}{ PH type } \\
\hline Idiopathic PAH & $10(36)$ & $3(37)$ & 7 (35) & \\
\hline Associated $\mathrm{PAH}^{\circ}$ & $10(36)$ & $4(50)$ & $6(30)$ & 0.44 \\
\hline CTEPH & $8(28)$ & $1(13)$ & 7 (35) & \\
\hline \multicolumn{5}{|l|}{ Specific therapy } \\
\hline No & $12(43)$ & $4(50)$ & $8(40)$ & 0.69 \\
\hline Yes & $16(57)$ & $4(50)$ & $12(60)$ & \\
\hline Oral therapy alone & 9 & 0 & 9 & \\
\hline Bosentan $^{+}$ & 10 & 0 & 10 & \\
\hline Sildenafil ${ }^{+}$ & 2 & 1 & 1 & \\
\hline Epoprostenol $^{+}$ & 5 & 3 & 2 & \\
\hline Other prostanoids ${ }^{\S}$ & 2 & 1 & 1 & \\
\hline CCBs & 1 & 0 & 1 & \\
\hline \multicolumn{5}{|l|}{ NYHA class } \\
\hline $1-11$ & $21(75)$ & $4(50)$ & $17(80)$ & 0.14 \\
\hline III & $7(25)$ & $4(50)$ & $3(20)$ & \\
\hline 6MWD m & $388 \pm 114$ & $311 \pm 140$ & $411 \pm 99$ & 0.058 \\
\hline \multicolumn{5}{|l|}{ Haemodynamics } \\
\hline $\bar{P}$ pa $\mathrm{mmHg}$ & $43 \pm 12$ & $44 \pm 13$ & $43 \pm 12$ & 0.77 \\
\hline Pra mmHg & $6.3 \pm 4.0$ & $6.2 \pm 4.1$ & $6.3 \pm 3.9$ & 0.93 \\
\hline Ppcw mmHg & $9.0 \pm 3.0$ & $9.3 \pm 3.9$ & $8.6 \pm 2.7$ & 0.59 \\
\hline $\mathrm{Cl} \mathrm{L} \cdot \mathrm{min}^{-1} \cdot \mathrm{m}^{-2}$ & $3.25 \pm 0.68$ & $3.28 \pm 0.52$ & $3.24 \pm 0.75$ & 0.89 \\
\hline $\mathrm{SVI} \mathrm{mL} \cdot \mathrm{m}^{-2}$ & $42 \pm 10$ & $38 \pm 8$ & $43 \pm 10$ & 0.25 \\
\hline PVRI WU $\cdot \mathrm{m}^{-2}$ & $11.1 \pm 5.7$ & $10.0 \pm 4.6$ & $11.5 \pm 6.1$ & 0.60 \\
\hline $\mathrm{Sv}, \mathrm{O}_{2} \%^{f}$ & $66 \pm 6$ & $71 \pm 6$ & $64 \pm 6$ & 0.05 \\
\hline
\end{tabular}

Data are presented as $n(\%)$, mean \pm SD or $n$, unless otherwise stated. POC: perioperative complication; $\mathrm{PAH}$ : pulmonary arterial hypertension; $\mathrm{CTEPH}$ : chronic thromboembolic pulmonary hypertension; CCB: calcium channel blocker; NYHA: New York Heart Association; 6MWD: 6-min walking distance Ppa: mean pulmonary arterial pressure; Pra: right atrial pressure; Ppcw: pulmonary capillary wedge pressure; $\mathrm{Cl}$ : cardiac index; SVI: stroke volume index; PVRI: indexed pulmonary vascular resistance; WU: Wood unit; $\mathrm{Sv}_{1} \mathrm{O}_{2}$ : mixed venous oxygen saturation. ${ }^{\#}$ : up to day 28 ; ": comprising five portopulmonary hypertension, three connective tissue disease-associated $\mathrm{PAH}$ and two HIV-associated PAH patients; ${ }^{+}$: includes patients on combination

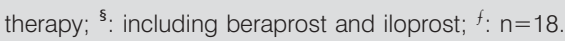

\section{Prognostic factors}

There was no significant difference in age or PH aetiology between patients who had and did not have perioperative complications. There was a suggestion that patients in NYHA class I-II preoperatively were less likely to exhibit perioperative complications than those in NYHA class III-IV $(n=17$ $(80 \%)$ versus $n=3(20 \%)$, respectively; $p=0.14)$, and that patients with a higher preoperative 6MWD (411 \pm 99 versus $311 \pm 140 \mathrm{~m} ; \mathrm{p}=0.058)$ showed fewer complications. However, there was no significant difference in resting preoperative haemodynamics between these patient groups. There was no influence of the use of all PH-specific therapy on complications, although no complications occurred in patients receiving oral therapy alone $(n=9)$ (table 3$)$. 


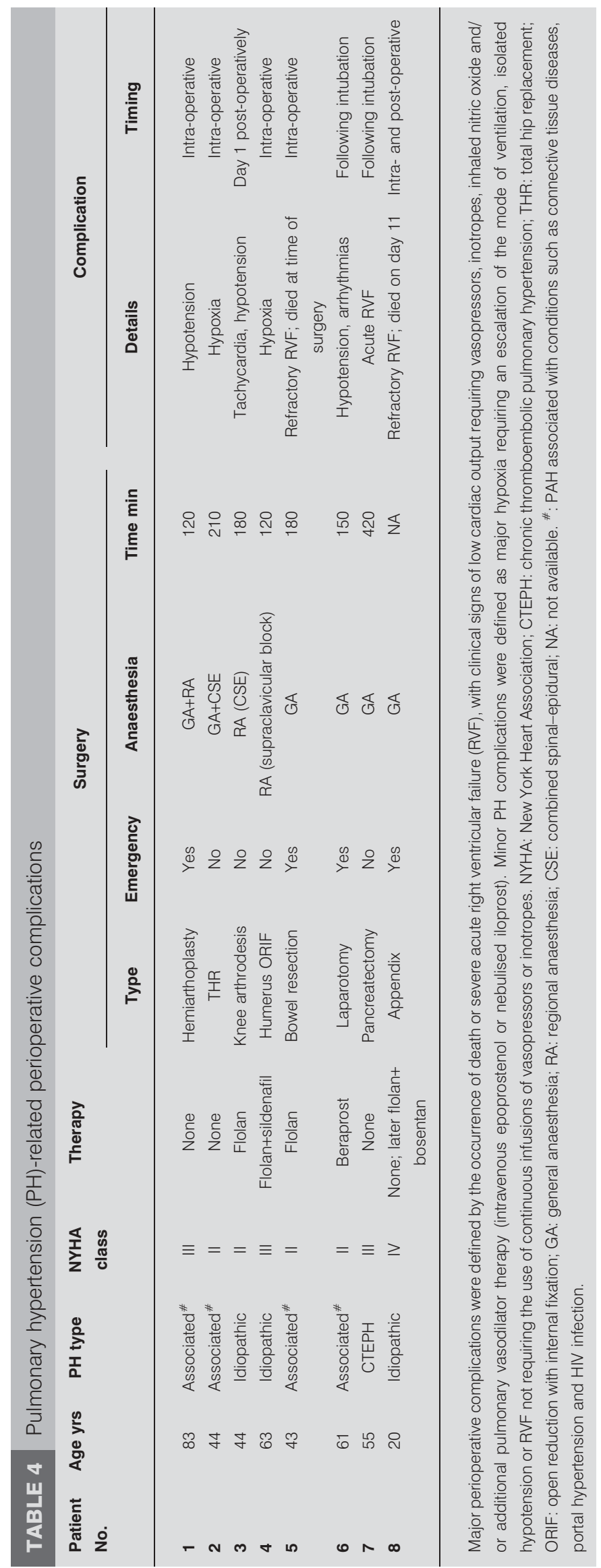

There was a suggestion that more perioperative complications occurred in procedures performed under GA compared to RA ( $n=6(75 \%)$ versus $n=2(25 \%)$, respectively; $p=0.12)$. Procedures with associated perioperative complications were longer than uncomplicated procedures (193 (120-420) versus $112(45-465) \mathrm{min} ; \mathrm{p}=0.003)$. More patients undergoing central venous pressure or intra-arterial monitoring $(n=3 ; 38 \%)$ and in whom CO monitoring (using pulmonary artery catheterisation (PAC) or oesophageal Doppler) was used $(n=3 ; 38 \%)$ had complications than those without (0 and 5\%, respectively) (table 2).

In patients undergoing $\mathrm{GA}$, there was no significant difference in $\mathrm{FI}, \mathrm{O}_{2}$ between patients with $(0.60 \pm 0.12)$ and without perioperative complications $(0.59 \pm 0.20)$, and three $(38 \%)$ patients with complications were given the supplemental anaesthetic agent nitrous oxide compared to one (5\%) of those without complications. High peak end-tidal carbon dioxide tension $\left(P E T, \mathrm{CO}_{2}\right)$ and peak airway pressure were not significantly associated with perioperative complications $(p=0.17$ and $\mathrm{p}=0.51$, respectively) (table 2 ).

\section{Longer term outcomes}

When perioperative deaths were excluded, the remaining survivors $(n=26)$ showed no evidence of significant clinical or haemodynamic deterioration at 3-6 months of follow-up. At preoperative baseline, 19 (73\%) out of 26 survivors were in NYHA functional class I-II compared with 22 (85\%) out of 26 at 3-6 months of follow-up $(\mathrm{p}=0.31)$. Accordingly, seven $(27 \%)$ out of 26 patients were in NYHA functional class III-IV before surgery and four (15\%) at follow up (including one patient in NYHA functional class IV) $(p=0.77)$ (table 5). Only two $(8 \%)$ patients had their PAH therapy increased over this period. There was no significant worsening of 6MWD $(n=17)$ or haemodynamics $(n=11)$ for those in whom follow-up data were available at 3-6 months. Even for the six patients who suffered perioperative complications and survived, NYHA functional class, 6MWD and haemodynamic assessment were unchanged at 3-6 months (data not shown). Furthermore, there was no significant deterioration in clinical status in survivors assessed at 6-12 months, whether or not perioperative complications had occurred (fig. 1).

\section{DISCUSSION}

In the present single-centre study, anaesthetic management, perioperative complications and $\mathrm{PH}$ outcomes are described in a high-risk population undergoing noncardiothoracic nonobstetric surgery. In this cohort of well-characterised patients with mostly mild-to-moderate PAH and non-operable CTEPH, overall perioperative mortality was $7 \%$, and the incidence of perioperative complications up to day 28 was $29 \%$. These are relatively high adverse event rates despite operating on mostly nonsevere patients in an experienced $\mathrm{PH}$ centre.

Data on complications and mortality following noncardiothoracic nonobstetric surgery in this population are rare, with only two previous single-centre studies available. One study of 145 patients showed that the perioperative mortality and 30-day morbidity rates were 7 and $42 \%$, respectively, for patients of similar NYHA functional class undergoing similar surgical procedures under GA, although this study did not include such well-characterised patients with regard to $\mathrm{PH}$ classification: 


\begin{tabular}{|c|c|c|c|}
\hline \multicolumn{4}{|c|}{ TABLE 5 Follow-up data } \\
\hline & Baseline & 3-6 months & $\mathrm{p}$-value \\
\hline \multicolumn{4}{|l|}{ Clinical status } \\
\hline NYHA I-II & $19(73)$ & $22(85)$ & 0.31 \\
\hline NYHA III-IV & $7(27)$ & $4(15)$ & \\
\hline Increase in therapy & & $2(8)$ & \\
\hline 6MWD m & $382 \pm 112$ & $387 \pm 124$ & 0.77 \\
\hline \multicolumn{4}{|l|}{ Haemodynamics $^{+}$} \\
\hline Pra $\mathrm{mmHg}$ & $7 \pm 4$ & $10 \pm 4$ & 0.06 \\
\hline PVRI WU $\cdot \mathrm{m}^{-2}$ & $14.50 \pm 5.60$ & $12.02 \pm 6.59$ & 0.04 \\
\hline Pिpa mmHg & $49 \pm 11$ & $46 \pm 12$ & 0.49 \\
\hline $\mathrm{CI} \mathrm{L} \cdot \mathrm{min}^{-1} \cdot \mathrm{m}^{-2}$ & $2.94 \pm 0.57$ & $3.54 \pm 1.18$ & 0.05 \\
\hline Ppcw mmHg & $8 \pm 3$ & $9 \pm 3$ & 0.31 \\
\hline $\mathrm{Sv}, \mathrm{O}_{2} \%^{\S}$ & $63 \pm 9$ & $59 \pm 11$ & 0.33 \\
\hline \multicolumn{4}{|c|}{ 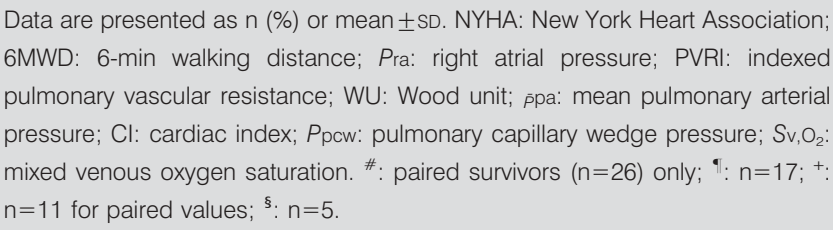 } \\
\hline
\end{tabular}

some of the patients had PH secondary to lung disease, and some were diagnosed using echocardiography without haemodynamic confirmation [9]. The second was a smaller study of well-characterised patients with more severe $\mathrm{PAH}$ than in the larger study ( $\bar{P}_{\text {pa }} 53 \pm 14 \mathrm{mmHg} ; 62 \%$ in NYHA class III-IV) undergoing 28 surgical procedures. These included 12 abdominal, six thoracic (including lung biopsy and resection but not endarterectomy), gynaecological and orthopaedic procedures, and $79 \%$ were performed under GA. Most complications reported related to the surgical procedure itself, with only $14 \%$ of cases complicated by reversible RVF, although deaths occurred in $18 \%$ of patients [11]. The lower overall mortality in the present study probably reflects the fact that patients had less severe disease, no thoracic procedures were performed and only $50 \%$ underwent GA compared to this last study. However, the mortality/complication rates of patients in the present study undergoing emergency or major procedures (100/50 and $13 / 50 \%$, respectively) were very high, and previous studies have not divided surgical procedures in this way to enable true comparisons.

Previous studies have suggested that RA may be safer than GA in patients with $\mathrm{PH}$, although this may, at least partly, be explained by reducing the risk imparted by GA. A recent series of $73 \mathrm{PAH}$ obstetric deliveries suggested that GA was associated with a four-fold increase in maternal mortality (univariate analysis; odds ratio 4.37; 95\% confidence interval 1.28-16.5; $p=0.02$ ) [22]. This has also been suggested in patients with Eisenmenger's syndrome, where, using 103 noncardiac anaesthetics, the perioperative mortality of those receiving GA was $18 \%$ compared to $5 \%$ in those undergoing RA, although this may well have been an indirect indicator of the increased mortality seen in major versus minor surgery (24 versus $5 \% ; \mathrm{p}<0.01$ ) as more patients undergoing GA also underwent more major surgery [29]. Patients with PAH that

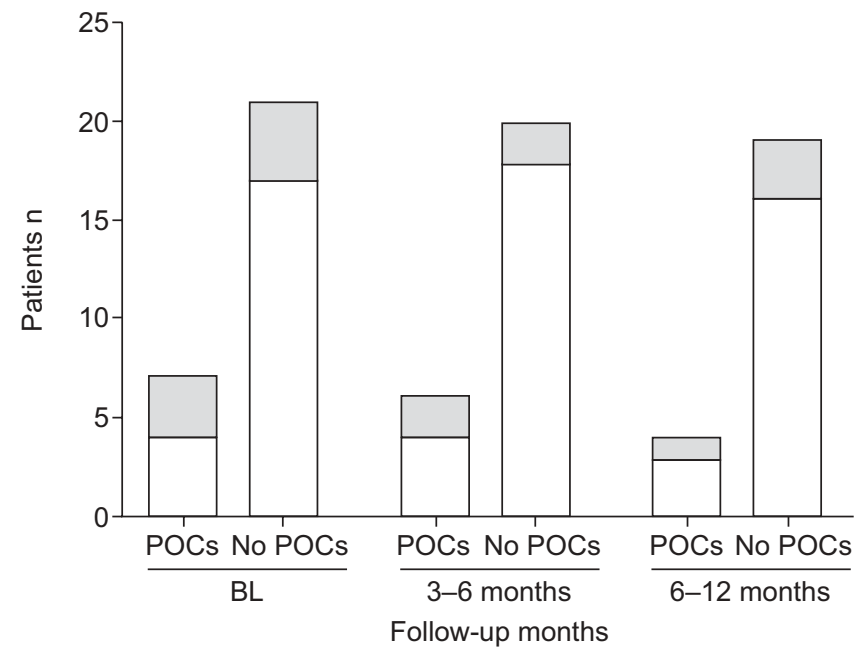

FIGURE 1. New York Heart Association (NYHA) functional class ( $\square$ : class I-II; I: class III-IV) of patients at baseline (BL) and after 3-6 and 6-12 months of followup, according to those suffering perioperative complications (POCs). At BL, $43 \%$ of patients with POCs were in NYHA class III-IV, compared to $19 \%$ of those without POCs. At 3-6 months of follow-up, there were similarly more patients with POCs in NYHA III-IV (33\% with POCs compared to 10\% without POCs). At 6-12 months of follow-up, $25 \%$ of those who had POCs were in NYHA class III-IV, and $16 \%$ of those without POCs. There was an increase in therapy in two patients at 3-6 months of follow-up, neither of whom had suffered a POC. At 12 months, three patients were receiving increased pulmonary arterial hypertension therapy, one of whom had suffered a POC

tolerate pregnancy have a particularly high perioperative risk, with a historical mortality of 36-50\% [21, 30], which, even in the modern treatment era, remains as high as $25 \%$ [22]. Obstetric operative deliveries were excluded from the present study for this reason. However, useful experience with obstetric RA can be extrapolated to the nonobstetric setting. Successful incremental regional blockade has been used in PAH obstetric deliveries [21], and is well tolerated by mothers with $\mathrm{PH}$ [31]. RA was previously thought harmful in patients with $\mathrm{PH}$ because of the haemodynamic compromise following sympathetic blockade; however, using a low intrathecal dose minimises this potential drop in afterload, and careful incremental epidural top-ups are well tolerated. RA techniques have also been useful in patients with $\mathrm{PH}$ in general surgery $[9$, 10]. RA may be an inappropriate anaesthetic technique, however, for many procedures, as well as in emergencies, when planned cessation of anticoagulation is not possible. In well-selected non-emergency patients undergoing suitable procedures, however, these data suggest relative safety of RA compared to GA in PH. The lack of reported bleeding at the site of neuraxial puncture, even in patients on epoprostenol, is notable, with the theoretical increased risk due to the antiplatelet aggregation effects of prostacyclins.

Both deaths reported in the present study followed refractory acute right heart failure, with one death intra-operatively and one at day 11. Most nonfatal complications occurred intra-operatively, and related in varying degrees to isolated RVF not requiring vasopressors and/or inotropes. Previous studies have shown that similar causes of perioperative death 
in patients undergoing noncardiac nonobstetric surgery may occur suddenly $[11,20]$ or up to $48 \mathrm{~h}$ following surgery [32]. Obstetric PAH deaths have been reported even up to 1 month after delivery [22], and guidelines suggest that obstetric patients should be monitored for at least $72 \mathrm{~h}$ post-operatively [33]. In the present study, perioperative complications related to $\mathrm{PH}$ and death were recorded over a 28-day post-operative period, with most of the complications occurring in the first $48 \mathrm{~h}(11(92 \%)$ out of 12$)$.

In the present study, significant univariate predictive factors for perioperative complications, including death, were found to be emergency surgery, major surgery and long operative time. Increased risk was suggested by the use of GA rather than RA, more severe preoperative NYHA functional class and a shorter 6MWD. Preoperative resting invasive haemodynamics were not predictive of outcome, which may reflect the small sample size, or perhaps indicate that exercise end-points are more sensitive in this setting, which bears similarities to preoperative cardiopulmonary exercise testing in the general surgical population. In a prospective study of patients undergoing major abdominal surgery (including those aged $<60$ yrs with cardiac disease), the preoperative anaerobic threshold (AT) predicted outcome, such that no patients died when the AT was $>11 \mathrm{~mL} \cdot \mathrm{min}^{-1} \cdot \mathrm{kg}^{-1}$, but $4.6 \%$ died when the AT was $<11 \mathrm{~mL} \cdot \mathrm{min}^{-1} \cdot \mathrm{kg}^{-1}$ [34]. The AT was used as it is independent of patient effort and occurs well below maximal oxygen uptake, the more usually recorded value in $\mathrm{PH}$, where a maximal oxygen uptake of $<10 . \mathrm{mL} \cdot \mathrm{min}^{-1} \cdot \mathrm{kg}^{-1}$ has been shown to predict poor survival [35]. It would be useful to know from future studies whether an AT above a certain threshold was also predictive of better surgical outcomes in this specific patient population.

There was a suggestion that patients monitored for CO (using either PAC or oesophageal Doppler) had more complications, although these are likely to indicate the more complex patients. Intra-operative invasive haemodynamic monitoring is not without risk, with both arrhythmias and pulmonary artery thrombosis and rupture reported [36], although using PAC is useful, with falling $\mathrm{CO}$ and $\bar{P}_{\mathrm{pa}}$ and rising CVP being markers of acute right ventricular decompensation [25]. The perioperative use of PAC in patients with $\mathrm{PH}$ is therefore debated. With the background that many complications are potentially avoidable, and that good teamwork improves outcomes, a recent study in noncardiac surgery has shown that use of a standardised safety checklist reduced complications [37].

The present study has suggested that the use of GA, as compared to RA, was associated with worse outcomes. Most patients receiving GA were undergoing emergency or major surgery, known to be associated with worse outcomes [38], and these are likely to be major confounding factors. However, there were more severe patients undergoing RA, indicated by both haemodynamics and the fact that significantly more patients on specific PAH therapy received RA than GA. The use of GA may increase PVR through several mechanisms, including increased sympathetic stimulation during airway instrumentation on laryngoscopy [39], effects of volatile agents [40], high airway plateau pressure due to the effects of positive-pressure mechanical ventilation [12, 13], hypoxia [15] and hypercapnia [16]. The present data suggested that more complications occurred in those with higher $P \mathrm{ET}, \mathrm{CO}_{2}$ and peak airway pressure, although many confounding factors may affect these values. Volatile anaesthetic agents may also adversely affect right ventricular preload and contractility [25], as well as afterload [40], although isoflurane has been used safely in human PAH [41]. Desflurane appears to exert worse pulmonary vascular effects than isoflurane, probably through sympathetic activation [42, 43]. Some studies suggest that nitrous oxide as a supplemental anaesthetic agent may increase PVR, especially in those with pre-existing elevated PVR [44], and it may also adversely influence endothelial function [45]. An increase in adverse cardiovascular events following its use in major surgery has been observed [46], possibly also through adverse pulmonary vascular effects of increased sympathomimetic stimulation [47, 48] or hypoxia [49], and a study addressing these questions is ongoing [50].

Despite the fact that patients experiencing complications showed worse functional capacity, longer term $\mathrm{PH}$ outcomes (including 6MWD, NYHA class and haemodynamics) at 36 months were not adversely influenced by having undergone surgery. For those in whom data were available at 612 months, NYHA functional class was similarly unchanged. The occurrence of perioperative complications did not adversely influence these outcomes. This is likely to relate to appropriate patient selection and perioperative management of complications in those that survived. These data suggest that the risk of procedures was associated with perioperative complications, and the possibility of occurrence of complications related to $\mathrm{PH}$ may not influence the progression of the disease following the perioperative period, suggesting that essential surgical procedures may not always be contraindicated in patients with stable $\mathrm{PH}$.

In addition to the confounding influence of surgical disease severity and type of surgery performed, limitations to the present study include its retrospective nature. However, selection bias was minimised by examining consecutive cases. A further limitation relates to the small sample size, preventing the use of multivariate analysis. The potential influence of GA, in addition to surgical type, on $\mathrm{PH}$ complications would require much larger patient numbers. This retrospective study does, however, emphasise several issues, which will be further addressed in an ongoing prospective international multicentric registry.

In conclusion, the present study has shown that the incidence of complications associated with noncardiothoracic nonobstetric surgery remains high, even in patients with mild-to-moderate $\mathrm{PAH}$, especially in those undergoing longer operations, emergency and major procedures, and those performed under GA, with most occurring within the first $48 \mathrm{~h}$ following surgery. The suggestion that more patients with worse functional status had more complications indicates that assessment of exercise tolerance should form part of preoperative examination. RA may be a safe approach in appropriately selected patients. Perioperative deaths occurred, especially following emergency procedures, but the mortality rate remains lower than following obstetric operative deliveries in patients with $\mathrm{PH}[22,30]$. Longterm follow up after surgery suggested no disease deterioration in surviving patients. Non-emergency procedures may not necessarily be contraindicated in appropriately selected $\mathrm{PH}$ 
patients if managed in an experienced $\mathrm{PH}$ centre during the pre-, peri- and post-operative periods.

\section{SUPPORT STATEMENT}

This study was supported, in part, by grants from the Ministry of Higher Education and Research and the University of Paris-South 11 (both Paris, France) to D. Montani. L.C. Price was supported by a European Respiratory Society (ERS) Long-term Research Fellowship (no. 139)

\section{STATEMENT OF INTEREST}

Statements of interest for D. Montani, X. Jaïs, G. Simonneau, O. Sitbon and M. Humbert can be found at www.erj.ersjournals.com $/ \mathrm{misc} /$ statements.dtl

\section{REFERENCES}

1 McGoon M, Gutterman D, Steen V, et al. Screening, early detection, and diagnosis of pulmonary arterial hypertension: ACCP evidence-based clinical practice guidelines. Chest 2004; 126: Suppl. 1, 14S-34S.

2 Rubin LJ. Primary pulmonary hypertension. N Engl J Med 1997; 336: 111-117.

3 Galie N, Hoeper MM, Humbert M, et al. Guidelines for the diagnosis and treatment of pulmonary hypertension. Eur Respir $J$ 2009; 34: 1219-1263.

4 Simonneau G, Galie N, Rubin LJ, et al. Clinical classification of pulmonary hypertension. J Am Coll Cardiol 2004;43, 12: Suppl. 1, 5S-12S.

5 Thenappan T, Shah SJ, Rich S, et al. A USA-based registry for pulmonary arterial hypertension: 1982-2006. Eur Respir J 2007; 30: $1103-1110$.

6 Humbert M, Sitbon O, Chaouat A, et al. Pulmonary arterial hypertension in France: results from a national registry. Am J Respir Crit Care Med 2006; 173: 1023-1030.

7 Reich DL, Bodian CA, Krol M, et al. Intraoperative hemodynamic predictors of mortality, stroke, and myocardial infarction after coronary artery bypass surgery. Anesth Analg 1999; 89: 814-822.

8 Reich DL, Wood RK Jr, Emre S, et al. Association of intraoperative hypotension and pulmonary hypertension with adverse outcomes after orthotopic liver transplantation. J Cardiothorac Vasc Anesth 2003; 17: 699-702.

9 Ramakrishna G, Sprung J, Ravi BS, et al. Impact of pulmonary hypertension on the outcomes of noncardiac surgery: predictors of perioperative morbidity and mortality. J Am Coll Cardiol 2005; 45: 1691-1699.

10 Lai HC, Lai HC, Wang KY, et al. Severe pulmonary hypertension complicates postoperative outcome of non-cardiac surgery. $\mathrm{Br} \mathrm{J}$ Anaesth 2007; 99: 184-190.

11 Minai OA, Venkateshiah SB, Arroliga AC. Surgical intervention in patients with moderate to severe pulmonary arterial hypertension. Conn Med 2006; 70: 239-243.

12 O'Hare R, McLoughlin C, Milligan K, et al. Anaesthesia for caesarean section in the presence of severe primary pulmonary hypertension. Br J Anaesth 1998; 81: 790-792.

13 Blaise G, Langleben D, Hubert B. Pulmonary arterial hypertension: pathophysiology and anesthetic approach. Anesthesiology 2003; 99: 1415-1432.

14 Bristow MR, Zisman LS, Lowes BD, et al. The pressure-overloaded right ventricle in pulmonary hypertension. Chest 1998; 114: Suppl. 1, 101S-106S.

15 Moudgil R, Michelakis ED, Archer SL. Hypoxic pulmonary vasoconstriction. J Appl Physiol 2005; 98: 390-403.

16 Balanos GM, Talbot NP, Dorrington KL, et al. Human pulmonary vascular response to $4 \mathrm{~h}$ of hypercapnia and hypocapnia measured using Doppler echocardiography. J Appl Physiol 2003; 94: 1543-1551.
17 Jardin F, Brun-Ney D, Cazaux P, et al. Relation between transpulmonary pressure and right ventricular isovolumetric pressure change during respiratory support. Cathet Cardiovasc Diagn 1989; 16: 215-220.

18 Irita K, Kawashima Y, Iwao Y, et al. [Annual mortality and morbidity in operating rooms during 2002 and summary of morbidity and mortality between 1999 and 2002 in Japan: a brief review.] Masui 2004; 53: 320-335.

19 Inoue $\mathrm{S}$, Abe $\mathrm{T}$, Yamada $\mathrm{A}$, et al. [A case of pulmonary hypertensive crisis (PHC) treated with prostaglandin $\mathrm{E}_{1}$ and tolazolin after surgery of ventricular septal defect in an adult.] Kyobu Geka 1994; 47: 1007-1011.

20 Rodriguez RM, Pearl RG. Pulmonary hypertension and major surgery. Anesth Analg 1998; 87: 812-815.

21 Bonnin M, Mercier FJ, Sitbon O, et al. Severe pulmonary hypertension during pregnancy: mode of delivery and anesthetic management of 15 consecutive cases. Anesthesiology 2005; 102: 1133-1137.

22 Bedard E, Dimopoulos K, Gatzoulis MA. Has there been any progress made on pregnancy outcomes among females with pulmonary arterial hypertension? Eur Heart J 2009; 30: 256-265.

23 Limsuwan A, Wanitkul S, Khosithset A, et al. Aerosolized iloprost for postoperative pulmonary hypertensive crisis in children with congenital heart disease. Int J Cardiol 2008; 129: 333-338.

24 Adatia I, Perry S, Landzberg M, et al. Inhaled nitric oxide and hemodynamic evaluation of patients with pulmonary hypertension before transplantation. J Am Coll Cardiol 1995; 25: 1656-1664.

25 Forrest P. Anaesthesia and right ventricular failure. Anaesth Intensive Care 2009; 37: 370-385.

26 Humbert M, Sitbon O, Simonneau G. Treatment of pulmonary arterial hypertension. $N$ Engl J Med 2004; 351: 1425-1436.

27 ATS Committee on Proficiency Standards for Clinical Pulmonary Function Laboratories: ATS statement: guidelines for the sixminute walk test. Am J Respir Crit Care Med 2002; 166: 111-117.

28 Sitbon $\mathrm{O}$, Humbert $\mathrm{M}$, Nunes $\mathrm{H}$, et al. Long-term intravenous epoprostenol infusion in primary pulmonary hypertension: prognostic factors and survival. J Am Coll Cardiol 2002; 40: 780-788.

29 Martin JT, Tautz TJ, Antognini JF. Safety of regional anesthesia in Eisenmenger's syndrome. Reg Anesth Pain Med 2002; 27: 509-513.

30 Weiss BM, Zemp L, Seifert B, et al. Outcome of pulmonary vascular disease in pregnancy: a systematic overview from 1978 through 1996. J Am Coll Cardiol 1998; 31: 1650-1657.

31 Dob DP, Yentis SM. UK registry of high-risk obstetric anaesthesia: report on cardiorespiratory disease. Int J Obstet Anesth 2001; 10 267-272.

32 Carmosino MJ, Friesen RH, Doran A, et al. Perioperative complications in children with pulmonary hypertension undergoing noncardiac surgery or cardiac catheterization. Anesth Analg 2007; 104: 521-527.

33 Uebing A, Steer PJ, Yentis SM, et al. Pregnancy and congenital heart disease. BMJ 2006; 332: 401-406.

34 Older P, Hall A, Hader R. Cardiopulmonary exercise testing as a screening test for perioperative management of major surgery in the elderly. Chest 1999; 116: 355-362.

35 Wensel R, Opitz CF, Anker SD, et al. Assessment of survival in patients with primary pulmonary hypertension: importance of cardiopulmonary exercise testing. Circulation 2002; 106: 319-324.

36 Barash PG, Nardi D, Hammond G, et al. Catheter-induced pulmonary artery perforation. Mechanisms, management, and modifications. J Thorac Cardiovasc Surg 1981; 82: 5-12.

37 Haynes AB, Weiser TG, Berry WR, et al. A surgical safety checklist to reduce morbidity and mortality in a global population. New Engl J Med 2009; 360: 491-499.

38 Tikkanen J, Hovi-Viander M. Death associated with anaesthesia and surgery in Finland in 1986 compared to 1975. Acta Anaesthesiol Scand 1995; 39: 262-267. 
PULMONARY CIRCULATION AND PULMONARY VASCULAR DISEASE

LC. PRICE ET AL.

39 Hickey PR, Retzack SM. Acute right ventricular failure after pulmonary hypertensive responses to airway instrumentation: effect of fentanyl dose. Anesthesiology 1993; 78: 372-376.

40 Kerbaul F, Rondelet B, Motte S, et al. Isoflurane and desflurane impair right ventricular-pulmonary arterial coupling in dogs. Anesthesiology 2004; 101: 1357-1362.

41 Chen DC, Edelist G. Isoflurane and primary pulmonary hypertension. Anaesthesia 1988; 43: 22-24.

42 Page PS, Eu JL, Damask MC, et al. Desflurane and isoflurane produce similar alterations in systemic and pulmonary hemodynamics and arterial oxygenation in patients undergoing one-lung ventilation during thoracotomy. Aaesth Analog 1998; 87: 800-807.

43 Ciofolo MJ, Rein S. Circulatory effects of volatile anesthetic agents. Minerva Anestesiol 1999; 65: 232-238.

44 Schulte-Sasse U, Hess W, Tarnow J. Pulmonary vascular responses to nitrous oxide in patients with normal and high pulmonary vascular resistance. Anesthesiology 1982; 57: 9-13.
45 Myles PS, Chan MT, Kaye DM, et al. Effect of nitrous oxide anesthesia on plasma homocysteine and endothelial function. Anesthesiology 2008; 109: 657-663.

46 Badner NH, Beattie WS, Freeman D, et al. Nitrous oxide-induced increased homocysteine concentrations are associated with increased postoperative myocardial ischemia in patients undergoing carotid endarterectomy. Anesth Analog 2000; 91: 1073-1079.

47 Bergofsky EH. Humoral control of the pulmonary circulation. Ann Rev Physio 1980; 42: 221-233.

48 Hickey PR, Hansen DD, Wessel DL, et al. Blunting of stress responses in the pulmonary circulation of infants by fentanyl. Anesth Analog 1985; 64: 1137-1142.

49 Myles PS, Leslie K, Gilbert B, et al. A review of the risks and benefits of nitrous oxide in current anaesthetic practice. Anaesth Intensive Care 2004; 32: 165-172.

50 Myles PS, Leslie K, Peyton P, et al. Nitrous oxide and perioperative cardiac morbidity (ENIGMA-II) Trial: rationale and design. Am Heart J 2009; 157: 488-494.

1302

VOLUME 35 NUMBER 6

EUROPEAN RESPIRATORY JOURNAL 